\title{
Spectrum of Cerebral Venous Thrombosis in Oman
}

Darshan Lal, ${ }^{1}$ "Arunodaya R. Gujjar, ${ }^{2}$ Nandagopal Ramachandiran, ${ }^{2}$ Ammar Obaidi, ${ }^{1}$ Sunil Kumar, Mortada El-Tigani, ${ }^{1}$ Faizal Al-Azri, ${ }^{3}$ Abdullah R. Al-Asmi ${ }^{1}$

$$
\text { أنواع التجلط الوعائي الوريدي الدماغي في سلطنة عمان }
$$

دارشان لال، أرونودايا غوجار، نانداجويال راماشاندران، عمار عبيدي، سونيل كومار، مرتضى التيجاني، فيصل العزري، عبد الله راشد العاصمي

ABSTRACT: Objectives: Cerebral venous thrombosis (CVT) can have varied and life-threatening manifestations. This study aimed to examine the spectrum of its clinical presentations and outcomes in a tertiary hospital in Oman. Methods: This retrospective study was conducted at the Sultan Qaboos University Hospital, Muscat, Oman, between January 2009 and December 2017. The medical records of all patients with CVT were reviewed to determine demographic characteristics, clinical features and patient outcomes. Results: A total of 30 patients had CVT. The mean age was $36.8 \pm 11$ years and the male-to-female ratio was 2:3. Common manifestations included headache (83\%), altered sensorium (50\%), seizures (43\%) and hemiparesis (33\%). Underlying risk factors were present in 16 patients (53\%). Computed tomography or magnetic resonance imaging of the brain was abnormal in all patients, with indications of infarcts (40\%) and major sinus thrombosis (100\%). There were five cases (20\%) of deep CVT. The patients were treated with low-molecular-weight heparin, mannitol and anticonvulsants. The majority (77\%) had no residual neurological deficits at follow-up. Conclusion: These findings indicate that CVT is a relatively uncommon yet treatable disorder in Oman. A high index of suspicion, early diagnosis, prompt anticoagulation treatment and critical care may enhance favourable patient outcomes.

Keywords: Venous Thrombosis; Cerebral Thrombosis; Cranial Venous Sinuses; Neurological Manifestations; Patient Outcome Assessment; Oman.

الملخص: الههف: التجلط الوريدي الدماغي له مظاهر متنوعة قد تهدد الحياة. هدفت هذه الدراسة إلى معرفة أنواع هذه الجلطات وأعراضها

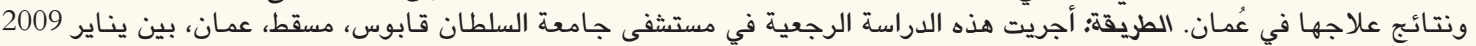

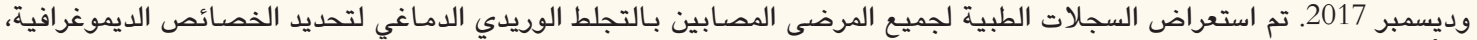

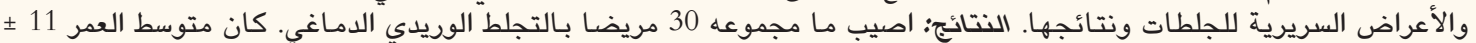

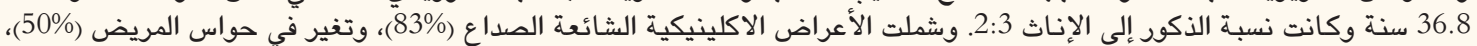

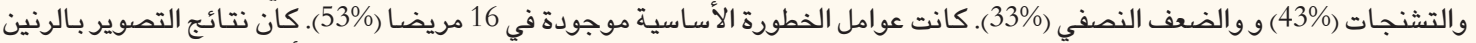

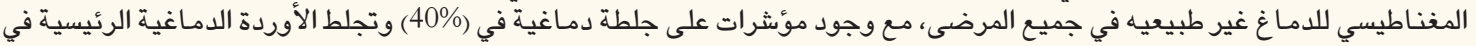

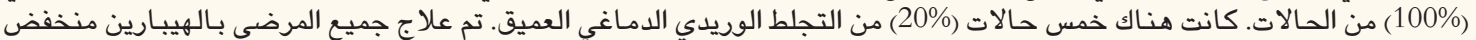

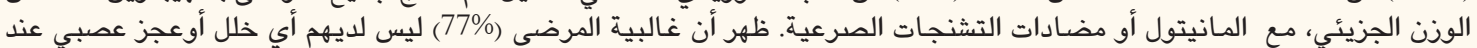

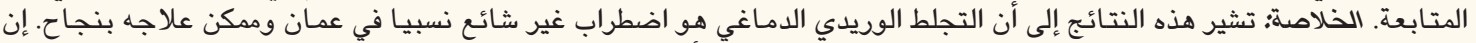

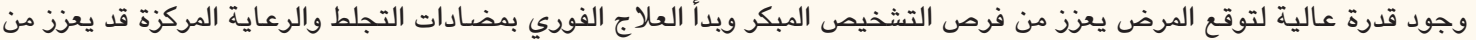

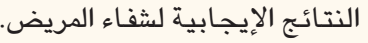
الكلمات المفتاحية: التجلط الوريدي؛ الجلطة الدماغية؛ الجيوب الوريدية الدماغية؛ الأعراض العصبية؛ تقييم نتائج المرضى؛ عمان.

\section{AdVANCES IN KNOWLEDGe}

This study reports the spectrum of cerebral venous thrombosis (CVT) in a tertiary hospital in Oman.

The approximate prevalence of CVT in the hospital-based cohort was 3\%. The CVT survivors had a relatively low incidence of residual neurological deficits (14.8\%).

\section{Application to Patient Care}

This study emphasises the need for greater awareness of the wide range of clinical manifestations of CVT and highlights the use of imaging to ensure the prompt diagnosis of this condition.

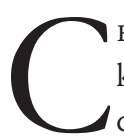

erebral Venous thrombosis (CVT)-ALSO known as cerebral sinovenous thrombosis or dural sinus thrombosis-constitutes approximately $0.5 \%$ of all stroke syndromes. ${ }^{1}$ The diverse manifestations of CVT can cause difficulties in diagnosis.
Moreover, the disease is potentially dangerous, with a large proportion of patients experiencing raised intracranial pressure (ICP), focal infarcts and intracerebral haemorrhage. ${ }^{1}$ Due to advances in the diagnostic sensitivity of imaging methods and the overall quality of 
management, CVT-related mortality has decreased from $>30 \%$ in 1960 to $5-15 \%$ in recent years. ${ }^{2}$ This study aimed to examine the spectrum of CVT in a tertiary hospital in Oman, including its clinical presentations and outcomes. In addition, representative cases are described to highlight various manifestations of CVT and challenges in the management of this condition.

\section{Methods}

This retrospective study was conducted at the Sultan Qaboos University Hospital (SQUH), Muscat, Oman, between January 2009 and December 2017. All adult patients ( $>18$ years old) diagnosed with CVT and entered into the hospital Stroke Registry were included in the study. Cases of cavernous sinus thrombosis were excluded due to their relation to infective conditions. In addition, patients with sinovenous disease related to trauma or local malignancy were also excluded.

Electronic medical records were systematically reviewed to collect demographic, clinical, imaging, treatment and outcome data. A CVT diagnosis was based on clinical features such as headaches, seizures, altered sensorium and focal neurological deficits, supported by imaging findings typical of sinovenous thrombosis. All patients were investigated for possible underlying thromboses. Other investigations included a complete blood count $(\mathrm{CBC})$ and coagulation profile as well as tests for autoimmune conditions and procoagulant states such as proteins $\mathrm{C}, \mathrm{S}$ and antithrombin III deficiencies and antiphospholipid syndrome.

This study received ethical approval from the Medical Research \& Ethics Committee of the College of Medicine \& Health Sciences, Sultan Qaboos University (MREC \#1062).

\section{Results}

A total of 900 patients with cerebrovascular disease were treated at SQUH during the study period, of which 30 (3\%) were diagnosed with CVT. The male-to-female ratio was 2:3 and the mean age was $36.8 \pm 11$ years old. The mean duration of symptoms was $7.4 \pm 3$ days, with 28 patients (93\%) having symptoms of $1-14$ days duration, while the remaining two patients had symptoms which evolved over a period of 30 and 45 days, respectively. The 28 patients were evaluated initially by the Emergency Medical Services, while the two patients with a longer duration of symptoms were admitted to the hospital ward. Headache was the most common symptom (83\%), followed by altered sensorium (50\%), seizures (43\%) and hemiparesis (33\%). The initial differential diagnosis included status epilepticus, arterial strokes, neuroinfections,
Table 1: Sociodemographic and clinical characteristics of cerebral venous thrombosis patients at the Sultan Qaboos University Hospital, Muscat, Oman (N = 30)

\begin{tabular}{|c|c|}
\hline Characteristic & n (\%) \\
\hline Mean age in years $\pm S D$ & $36.8 \pm 11$ \\
\hline \multicolumn{2}{|l|}{ Gender } \\
\hline Male & $12(40)$ \\
\hline Female & $18(60)$ \\
\hline \multicolumn{2}{|l|}{ Symptoms* } \\
\hline Headache & $25(83)$ \\
\hline Altered sensorium & $15(50)$ \\
\hline Seizures & $13(43)$ \\
\hline Hemiparesis & $10(33)$ \\
\hline Mean duration of symptoms in days \pm SD & $7.4 \pm 3$ \\
\hline Risk factors* & $16(53)$ \\
\hline Pregnancy/puerperium & $5(17)$ \\
\hline Systemic malignancy & $4(13)$ \\
\hline Oral contraceptive use & $2(7)$ \\
\hline SLE & $1(3)$ \\
\hline Protein C/anti-thrombin III deficiency & $2(7)^{+}$ \\
\hline None & $14(47)$ \\
\hline \multicolumn{2}{|l|}{ Treatment* } \\
\hline LMWH & $27(90)$ \\
\hline IV mannitol & $13(43)$ \\
\hline Anticonvulsant & $11(37)$ \\
\hline ICU care & $6(20)$ \\
\hline Warfarin & $21(70)$ \\
\hline \multicolumn{2}{|l|}{ Short-term outcome } \\
\hline Died during hospital stay & $3(10)$ \\
\hline Survived & $27(90)$ \\
\hline \multicolumn{2}{|l|}{ Long-term outcome } \\
\hline Complete recovery & $23(77)$ \\
\hline Neurological deficit & $4(13)$ \\
\hline \multicolumn{2}{|c|}{$\begin{array}{l}S D=\text { standard deviation; } S L E=\text { systemic lupus erythematosus; } \\
L M W H=\text { low-molecular } \text {-weight heparin; } I V=\text { intravenous; } \\
I C U=\text { intensive care unit. }\end{array}$} \\
\hline \multicolumn{2}{|c|}{$\begin{array}{l}\text { "Percentages do not add up to } 100 \% \text { as some patients may have had } \\
\text { more than one risk factor, symptom or treatment. Including one } \\
\text { patient with a protein C deficiency and one patient with an anti- } \\
\text { thrombin III deficiency. }\end{array}$} \\
\hline
\end{tabular}

intracerebral haemorrhage, mass lesions and cerebral angiitis, in addition to CVT. Risk factors were present in 16 patients (53\%), including pregnancy/puerperium (17\%), systemic malignancy (13\%), oral contraceptive use (7\%), systemic lupus erythematosus (3\%) and protein 
Table 2: Imaging features of cerebral venous thrombosis patients at the Sultan Qaboos University Hospital, Muscat, Oman $(\mathrm{N}=30)^{*}$

\begin{tabular}{lc} 
Feature & $\mathbf{n}(\%)^{\dagger}$ \\
CT & $25(83)$ \\
Abnormal & $21(84)$ \\
Parenchymal haemorrhage & $7(28)$ \\
Non-haemorrhagic/haemorrhagic infarct & $10(40)^{\ddagger}$ \\
Contrast CTV & $25(83)$ \\
TrS thrombosis & $12(48)$ \\
SSS thrombosis & $11(44)$ \\
SigS thrombosis & $8(32)$ \\
IJV thrombosis & $4(16)$ \\
SS thrombosis & $2(8)$ \\
Cortical vein thrombosis & $2(8)$ \\
Empty delta sign & $8(32)$ \\
MRI & $25(83)$ \\
Abnormal & $25(100)$ \\
Haemorrhage & $3(12)$ \\
Non-haemorrhagic/haemorrhagic infarct & $10(40)^{\S}$ \\
MRV & $25(83)$ \\
TrS thrombosis & $13(52)$ \\
SSS thrombosis & $11(44)$ \\
EigS thrombosis & $11(44)$ \\
IJV thrombosis & $5(20)$ \\
\hline
\end{tabular}

$C T=$ computed tomography; $C T V=$ computed tomography venography; $\operatorname{Tr} S$ = transverse sinus; SSS = superior sagittal sinus; SigS = sigmoid sinus; IJ $\mathrm{V}=$ internal jugular vein; $S S$ = straight sinus; $M R I=$ magnetic resonance imaging; $M R V=$ magnetic resonance venography.

*All patients had either CT or MRI brain scans, with 20 patients (67\%) undergoing both imaging modalities. ${ }^{\dagger}$ Percentages do not add up to $100 \%$ as some patients may have had more than one imaging feature. ${ }^{\ddagger}$ Comprising five patients with non-haemorrhagic infarcts and five patients with

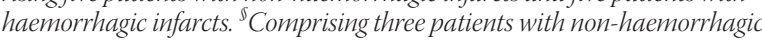
infarcts and seven patients with haemorrhagic infarcts.

$\mathrm{C}$ and anti-thrombin III deficiencies (7\%). Despite extensive investigations, no underlying cause could be established in the remaining 14 patients (47\%) [Table 1].

Either computed tomography (CT) or magnetic resonance imaging (MRI) of the brain was performed in all 30 patients, with the majority (67\%) undergoing both modalities. A total of 25 patients (83\%) underwent CT scans, which were abnormal in 21 patients (84\%). Parenchymal haemorrhage and infarcts were observed in $28 \%$ and $40 \%$ of patients, respectively.
Using contrast CT venography, transverse sinus $(\mathrm{TrS})$ thrombosis was seen in $48 \%$ of patients, superior sagittal sinus (SSS) thrombosis in $44 \%$, sigmoid sinus (SigS) thrombosis in 32\%, internal jugular vein (IJV) thrombosis in $16 \%$ and straight sinus (SS) and cortical vein thrombosis were each seen in $8 \%$ of patients. Empty delta sign was seen in eight patients (32\%). The MRI scans of all patients were abnormal. Infarcts were the most common MRI abnormality (40\%), followed by haemorrhage (12\%). Magnetic resonance venography (MRV) revealed $\mathrm{TrS}$ thrombosis in $52 \%$ of patients, SSS and SigS thrombosis in $44 \%$ each, cortical vein thrombosis in $20 \%$ and IJV and SS thrombosis in $8 \%$ each. Empty delta sign was observed in five patients (20\%) [Table 2].

With regards to treatment, 27 patients (90\%) received low-molecular-weight heparin (LMWH) in therapeutic doses over an initial 7-14-day period. A total of 13 patients (43\%) received intravenous (IV) mannitol and 11 (37\%) received anticonvulsants. Six patients (20\%) required intubation and ventilation in the intensive care unit (ICU) due to either an altered mental status or status epilepticus. A total of 21 patients (70\%) were prescribed warfarin for the purposes of long-term anticoagulation, adjusted to a target international normalised ratio (INR) of 2.3. This treatment was continued for periods ranging from three months for puerperal CVT cases to a year or longer for other conditions. Patients with either recurrent CVT or high-risk procoagulant states were advised to continue taking anticoagulation medications indefinitely.

Overall, 27 patients (90\%) survived. The remaining three patients (10\%) died due to either extensive thrombosis with malignant brain oedema, advanced malignancy or sepsis complicating a central nervous system infection. One patient underwent surgical evacuation of a hemispheric haematoma with perioperative recognition of the thrombosed veins; after one year, he was readmitted with recurrent CVT after having discontinued anticoagulation medications. At follow-up, 23 patients (77\%) showed complete neurological recovery. The following subsections highlight four different presentations of CVT seen during the study period.

\section{PUERPERAL CEREBRAL VENOUS THROMBOSIS}

A 23-year-old woman underwent an emergency Caesarean section due to severe pre-eclampsia at 29 gestational weeks. She had a family history of venous thrombotic events with a history of deep vein thrombosis (DVT) on her mother's side. Although she recovered promptly following the procedure, she presented 10 days later with a headache, left-sided weakness and recurrent generalised seizures progressing to status epilepticus. The seizures were controlled with IV phenytoin. An examination revealed drowsiness and left hemiparesis. 


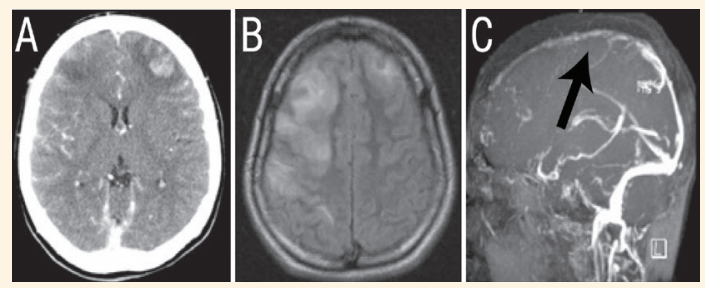

Figure 1: Imaging of the brain of a 23-year-old woman with puerperal cerebral venous thrombosis showing (A) mixed-density bifrontal venous infarcts on computed tomography, (B) increased involvement of the right hemisphere two days later on magnetic resonance imaging and $(\mathrm{C})$ thrombosis of the anterior two-thirds of the superior sagittal sinus (arrow) and right transverse sinus upon magnetic resonance venography.

A CT scan of the brain revealed bifrontal mixeddensity lesions suggestive of haemorrhagic venous infarcts [Figure 1A]. A contrast CT scan showed evidence of a filling defect in the SSS and left TrS, suggestive of dural venous thrombosis. Extensive investigations, including a factor VIII assay and tests for protein $\mathrm{C}$, protein $\mathrm{S}$ and anti-thrombin III deficiencies, were normal or negative. The patient was diagnosed with puerperal CVT and received a weight-based dosage of subcutaneous LMWH. However, an MRI scan of the brain two days later revealed diffuse oedema and an increase in the size of the right hemispheric infarction [Figure 1B]. An MRV confirmed thrombosis of the anterior part of the SSS and right $\operatorname{TrS}$ [Figure $1 \mathrm{C}]$.

After further treatment, the left hemiparesis improved gradually. The patient was discharged on warfarin treatment adjusted to an INR of 2.3, which she continued taking for one year. At a one-year follow-up, she appeared normal. Later, she received LMWH prophylactically during two subsequent uneventful pregnancies.

\section{RECURRENT CEREBRAL VENOUS THROMBOSIS}

A 60-year-old man presented with a two-day history of generalised severe headaches associated with vomiting and a generalised tonic-clonic seizure. He remained unresponsive after the seizure, with normal reactive pupils, left facial paresis and dense left-sided hemiparesis. There was no evidence of recent weight loss, trauma or alcohol abuse. The results of blood investigations, such as plasma glucose, $\mathrm{CBC}$, biochemistry and coagulation parameters, were normal.

A CT scan of the brain performed at admission showed patchy right parietal haemorrhage, a streak of blood in the left parietal cortical region and hyperdensity along the SSS [Figure 2A]. He received IV levetiracetam and mannitol and was managed in the ICU. The altered sensorium further worsened the next day. An MRI scan showed an increase in the size of the

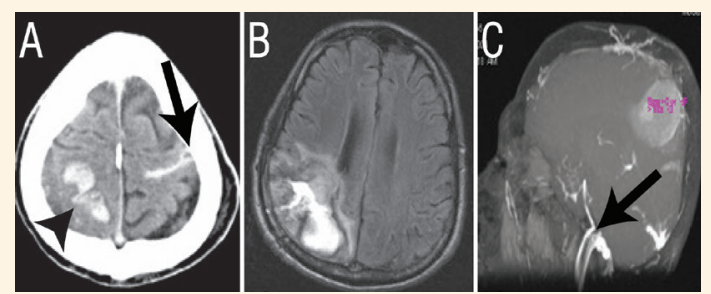

Figure 2: Imaging of the brain of a 60-year-old man with recurrent cerebral venous thrombosis showing (A) right parietal patchy haemorrhage, a thrombosed cortical vein in the left parietal region (arrow) and hyperdensity along the superior sagittal sinus (arrowhead) on computed tomography, (B) an increase in the size of the right parietal haematoma upon magnetic resonance imaging the next day and $(\mathbf{C})$ thrombosis of the superior sagittal sinus extending to the transverse and sigmoid sinuses and further into the right internal jugular vein (arrow) upon magnetic resonance venography.

right parietal haematoma with mass effects and a midline shift [Figure 2B]. An MRV confirmed thrombosis of the SSS extending to the TrS, SS and further into the right IJV [Figure 2C].

The patient underwent an emergency craniotomy with decompression of the right parietal haematoma. During the surgery, thrombosis of the cortical veins was confirmed. He received an enoxaparin sodium injection as well as IV mannitol and phenytoin. Further investigations for autoimmune conditions, procoagulant states and occult malignancies were negative. Despite the continuation of anticoagulation treatment, his ICU stay was complicated by DVT leading to extensive lower limb oedema, requiring the placement of an inferior vena cava filter.

Over the next two weeks, the patient's altered sensorium and left hemiplegia improved. He was advised to take warfarin on a long-term basis; however, he stopped after two years. A year later, he presented with a suddenonset severe headache, disorientation and generalised seizures without focal deficits. Brain CT and MRI scans showed a left temporal haemorrhagic infarct with surrounding oedema due to thrombosis of the vein of Labbé as well as the major sinuses. He was treated with levetiracetam, LMWH and IV mannitol. The patient improved with no overt neurological deficits and good functional recovery. He was advised to continue taking warfarin indefinitely.

\section{DEEP VEIN THROMBOSIS}

A 41-year-old woman presented to the emergency department with a one-day history of left-sided weakness, impaired speech and altered sensorium. There were no seizures. She reported having a history of oral contraceptive use of unspecified duration. Upon presentation, the patient was conscious but had difficulty finding words. Both pupils and optic fundi appeared normal. 

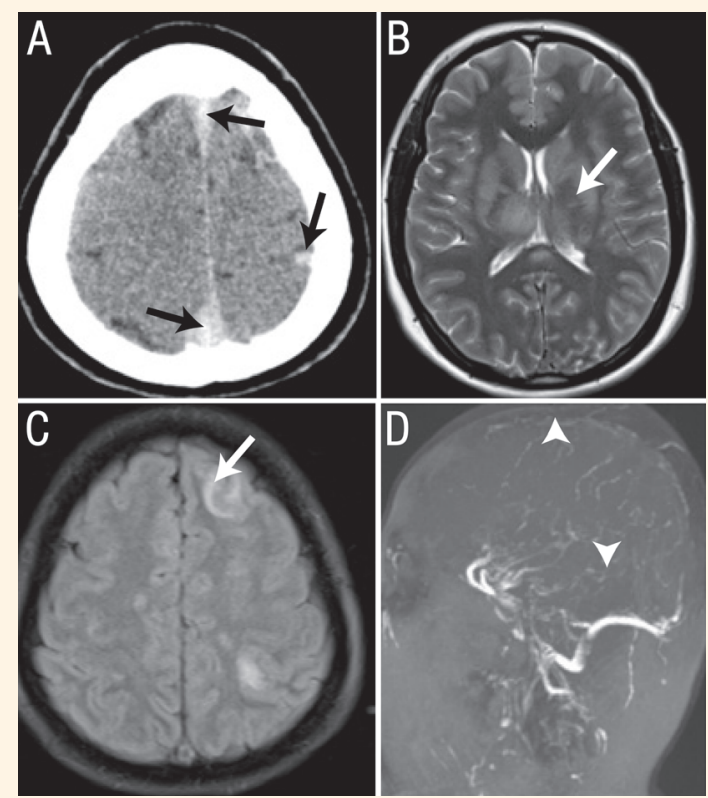

Figure 3: Imaging of the brain of a 41-year-old woman with deep cerebral venous thrombosis showing (A) thrombosis of the superior sagittal sinus (SSS) as well as the left frontal and parietal cortical veins (arrows) on computed tomography, (B) biconvex hyperintensities in the thalamus-basal ganglionic region (arrow) as well as $(C)$ cortical venous infarcts (arrow) upon magnetic resonance imaging the next day and (D) the absence of flow void in the deep venous system as well as the SSS (arrowheads) upon magnetic resonance venography.

She had left hypotonic hemiplegia but normal power on the right side. Her tendon reflexes were brisk and she had bilateral extensor plantar responses. Blood investigations revealed a haemoglobin level of $15.2 \mathrm{~g} / \mathrm{dL}$ with mild neutrophilic leukocytosis and a C-reactive protein level of $22 \mathrm{mg} / \mathrm{dL}$. The results of biochemistry tests were normal.

One day after the onset of symptoms, a brain CT scan showed mild diffuse oedema without acute infarcts or haemorrhage. However, the SSS was prominent and hyperintense, suggesting sinus thrombosis, with suspected cortical vein thrombosis in the left frontal and parietal regions [Figure 3A]. Therapeutic doses of $\mathrm{LMWH}$ were administered. However, the altered sensorium worsened the next day. The patient was drowsy and only opened her eyes in reaction to pain. An MRI of the brain showed bilateral parasagittal and frontoparietal hyperintensities as well as symmetrical hyperintensities in the basal ganglia and thalamus, typical of CVT involving the deep venous system [Figures $3 \mathrm{~B}$ and $\mathrm{C}$ ]. An MRV showed extensive thrombosis of the SSS and left TrS, SigS, bilateral parasagittal cortical veins as well as of the deep venous system [Figure 3D].

The patient received IV mannitol and a levetiracetam injection along with LMWH. A work-up for antinuclear antibodies (ANAs), antiphospholipid antibodies and thrombophilia was negative. Gradually, the patient's
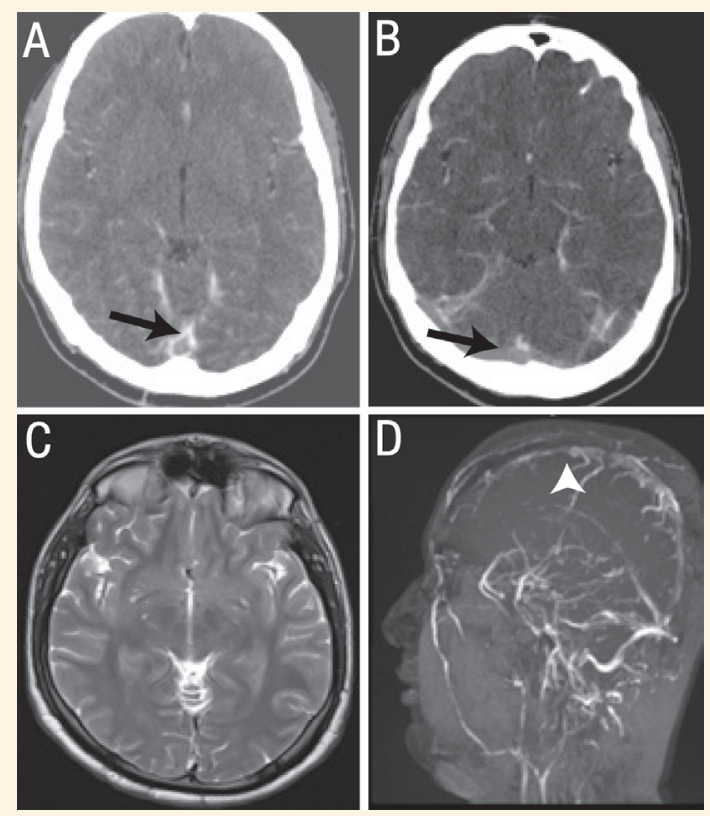

Figure 4: Imaging of the brain of a 21-year-old man with thrombosis restricted to the major dural venous sinuses showing (A) empty delta sign in the superior sagittal sinus (SSS) with surrounding contrast (arrow) and (B) thrombosis of the transverse sinus ( $\mathrm{TrS}$ ) (arrow) on computed tomography, (C) normal parenchyma upon magnetic resonance imaging and (D) thrombosis of the SSS and TrS upon magnetic resonance venography (arrowhead).

speech and motor functions improved with time. Eventually, the LMWH anticoagulant treatment was replaced with warfarin at a target INR of 2-3. At discharge, she was ambulant with no focal neurological deficits.

\section{RAISED INTRACRANIAL PRESSURE}

A 21-year-old man was admitted with a severe generalised headache of six days' duration, recurrent vomiting and double vision. He did not report any focal weakness, seizures or loss of consciousness. Upon examination, the patient was alert, with restricted abduction of the right eye and bilateral florid papilloedema, suggestive of raised ICP. At admission, a brain CT scan revealed no parenchymal changes; however, there was evidence of thrombosis of the SSS and TrS and empty delta sign [Figures 4A and B]. Additionally, MRI scans showed normal brain parenchyma as well as extensive thrombosis involving the SSS and TrS [Figures 4C and D].

The patient's haemoglobin level was $17.9 \mathrm{~g} / \mathrm{dL}$ and his haematocrit percentage was $49 \%$, consistent with a diagnosis of polycythaemia. However, his ANAs and antiphospholipid antibodies were normal and tests for C-protein, S-protein and antithrombin III deficiencies and the janus kinase 2 mutation were negative. No specific cause for the polycythaemia could be determined. The patient was treated with IV tramadol and subcutaneous LMWH. Repeated venesections were performed 
to reduce his haematocrit percentage. One week later, the patient reported that his headache had improved remarkably. The papilloedema and sixth cranial nerve palsy improved gradually. He was discharged with a prescription for warfarin.

\section{Discussion}

This study explores patterns of CVT presentation, diagnosis and outcomes among patients at a tertiary hospital in Oman. Despite the small number of cases, the majority of patients resembled previously reported series in most respects, such as onset in young adulthood, a female predominance, the rapid evolution of symptoms over a few days, a relatively low mortality rate and complete improvement among most survivors. ${ }^{1,3,4}$

As illustrated in the four representative cases described, CVT may present in certain recognisable syndromes which often correlate with patterns of cerebral vein or dural sinus involvement. ${ }^{4-7}$ Such presentations may include raised ICP/space-occupying lesion, acute stroke-like presentations, status epilepticus/seizures, diffuse encephalopathy, comas and, rarely, a posterior fossa syndrome. The first case had puerperal CVT, the most common form of CVT in developing countries. ${ }^{4,8}$ Despite its monomorphic clinical profile, no specific cause for puerperal CVT is yet recognised. ${ }^{8}$ The second and third cases illustrate the rapid evolution of CVT symptoms. The overall risk of relapse in CVT cases is $6.5 \%$, decreasing to $3 \%$ for patients with puerperal CVT. ${ }^{9,10}$ Recurrent CVT generally occurs more often among males, such as in the second case. ${ }^{6}$ In the third case, the patient developed CVT due to oral contraceptive use. This progressed to encephalopathy and altered sensorium and pyramidal signs signifying diencephalic dysfunction due to deep CVT. Other manifestations of deep venous system involvement include ophthalmoparesis, ptosis, decerebrate posturing, coma and movement disorders reflecting the regions drained by the affected veins. The fourth patient had isolated major dural sinus thrombosis without parenchymal changes, with symptoms of headache, papilloedema and sixth cranial nerve palsy; the latter is a classic example of a false localising sign.

Every patient with CVT should be investigated for an underlying cause or risk factor. ${ }^{11}$ Ovarian hormonal changes related to the puerperium, oral contraceptive use, haematological disorders, prothrombotic states and malignancy constitute common risk factors. In the context of pregnancy or soon after labour, changes in the coagulation cascade may play a role in CVT development; anaemia and dehydration may also be influencing factors, although puerperal CVT has not been associated with any specific procoagulant risk factor. ${ }^{4,8}$
The presence of certain risk factors may influence the duration of anticoagulation treatment. However, in most CVT series, there is no underlying cause or predisposing condition.

Ideally, MRI plus MRV is the preferred imaging approach to confirm a diagnosis of CVT.9,12,13 However, a cranial CT scan is often the initial investigation performed in emergency cases and can provide several indications of the correct diagnosis. Changes involving the venous structures as well as parenchymal changes may be seen on CT brain scans. Cord sign, dense triangle sign and empty delta sign are well-known direct signs of CVT. ${ }^{9,12,13}$ Cord sign appears as a linear hyperdensity on a non-contrast scan, usually on the cortical surface due to thrombosis of the cortical veins. A thrombus in the SS or vein of Galen may be similarly visualised., ${ }^{9,12,13}$ A dense triangle sign on a non-contrast CT scan is typically seen along the thrombosed SSS. On contrastenhanced CT scans, an empty delta sign-wherein the contrast flows around a central and relatively hypodense thrombus - can be observed in the dural venous sinus region in up to $60 \%$ of CVT cases. ${ }^{7}$ Indirect signs of $\mathrm{CVT}$ on $\mathrm{CT}$ occur due to the effects of venous or sinus thrombosis on the brain parenchyma. Although common, the specificity of such signs is low; thus, they may not be sufficient for a definitive diagnosis of CVT. Multiple non-haemorrhagic infarcts not conforming to an arterial territory or multifocal or confluent areas of haemorrhage are suggestive of CVT. Extensive brain oedema, compressed ventricles or bihemispheric hypodensities may be caused by thrombosis of the major sinuses or cortical veins; these features are seen in 25-42\% of CVT cases. ${ }^{12}$ Deep CVT gives rise to fairly typical biconvex diencephalic hypodensities with cord sign in the internal cerebral veins or SS. ${ }^{14,15}$

When used together, MRI and magnetic resonance angiography (MRA) have a high degree of sensitivity and specificity in the diagnosis of CVT. ${ }^{12}$ A gyriform pattern of venous infarcts, thrombosed cortical veins or venous sinuses, different temporal stages of haemorrhagic infarcts or haematomas and associated brain oedema may be observed. Acute parenchymal haemorrhage as well as thrombi located within the dural sinuses may vary in appearance over time, appearing isointense on $\mathrm{T} 1$ and $\mathrm{T} 2$ sequences in the first few days (due to the predominance of deoxyhaemoglobin in the clot), then hyperintense between days 5-15 (due to the formation of methaemoglobin), before becoming isointense again. ${ }^{6}$ MRV has the advantage of depicting most of the cerebral venous system noninvasively. Thrombosis most commonly affects the SSS (62\%) and $\operatorname{TrS}(41 \%)$, while the SS (18\%), deep venous system (11\%) and IJV (12\%) are less frequently involved. ${ }^{16}$ Two direct signs of CVT 
on MRA images are the absence of high flow in the dural sinus region which is not hypo- or aplastic and a 'frayed' flow signal in the sinus region after partial recanalisation. Dilated collateral medullary veins and prominent emissary veins crossing the skull may also be observed in later stages. ${ }^{4}$ Conventional angiography, preferably digital subtraction angiography, is useful in patients with equivocal signs on other modes of imaging.

The management of CVT has evolved significantly in the last few decades. ${ }^{2}$ Prompt diagnosis and treatment have been shown to drastically reduce mortality and improve outcomes, even in the presence of intracerebral haemorrhage, as in the first case described in the current study. ${ }^{4}$ Anticoagulation treatment, typically with LMWH, is the standard of care, despite limited evidence to support its use. ${ }^{11,13,17,18}$ Weight-based dosing for anticoagulants significantly improves outcomes and reduces mortality, even among patients with haemorrhagic infarcts or haematomas. ${ }^{11,13,17,18}$ Overall, LMWH may be safer than unfractionated heparin, although the latter may be preferable perioperatively. ${ }^{17}$ Patients should be monitored closely for evidence of haemorrhage or heparin-induced thrombocytopaenia.

Anticerebral oedema measures such as mannitol, hypertonic saline or hyperventilation may be required for the emergent control of raised ICP, particularly for patients with extensive infarctions involving the major dural sinuses; however, the benefits of these measures have not yet been systematically evaluated. ${ }^{18,20}$ Anticonvulsants are clearly indicated among patients with seizures; moreover, due to the high incidence of seizures in CVT (35-50\%), some researchers recommend prescribing these prophylactically., 511,19 Steroids and acetazolamide are not beneficial in CVT treatment. ${ }^{9}$

Novel approaches such as surgical decompression and intrasinus thrombolysis or thrombectomies have been explored in select cases of CVT.11,18 Patients with lateral or focal brain oedema due to infarction/haemorrhage or thrombosed veins causing mass effects and impending herniation should be considered in a timely manner for an emergency decompressive craniectomy. Such surgical interventions may require the transient interruption of anticoagulation measures. In a previous series of 56 CVT patients with large infarcts causing significant mass effects, decompressive craniectomies resulted in good outcomes in 54\% of cases. ${ }^{20}$ However, $25 \%$ of the patients died. Poor outcomes were associated with coma at admission, advanced age, a need for ventilation and severe neurological deficits. ${ }^{20}$ Other studies have reported better mortality and functional recovery rates following surgical intervention. ${ }^{21,22}$

Endovascular interventions such as thrombolysis or a thrombectomy have been utilised in thrombosis mainly involving the major dural venous sinuses causing raised ICP and not improving following an initial anticoagulation trial. ${ }^{20-26}$ An endovascular catheter is placed inside the clot to deliver an infusion of actilyse for thrombolysis or a mechanical clot-retrieving instrument may be used for mechanical throbectomy. ${ }^{25}$ A multicentre randomised clinical trial was initiated in 2013 to compare the effectiveness of endovascular thrombectomy in comparison with anticoagulant therapy; unfortunately, it was prematurely terminated in $2016 .{ }^{25}$ A retrospective study found that the intrasinus infusion of a thrombolytic agent with mechanical thrombectomy in 29 patients with dural sinus thrombosis resulted in similar 90-day outcomes to those of 37 patients treated with anticoagulants alone. ${ }^{26}$

Long-term anticoagulation treatment, usually involving warfarin titrated to an INR of $2-3$, is recommended to prevent recurrent venous thrombosis as well as other complications such as a pulmonary embolism. ${ }^{9,13}$ However, due to a lack of randomised trials, recommendations for long-term anticoagulation are mostly based on expert consensus. In puerperal or oral contraceptive-associated CVT, anticoagulants are recommended for 12 weeks after an initial course of heparin; thereafter, subcutaneous LMWH is recommended during subsequent pregnancies to prevent recurrence. ${ }^{27}$ Patients with CVT provoked by specific triggers (e.g. infections, medication or catheter placement) or those with no risk factors for possible recurrence should be treated with anticoagulants for 6-12 months. In contrast, oral anticoagulants are continued indefinitely among patients with recurrent CVT or those with severe prothrombotic states such as antiphospholipid syndrome or genetic thrombophilias. While newer oral anticoagulants have been studied, there is currently insufficient evidence to recommend their use. ${ }^{28}$

In recent decades, the overall prognosis for patients with CVT has improved, likely due to early anticoagulation measures and improvements in the quality of critical care. ${ }^{2,4,29}$ Although CVT is three times more common among women, the prognosis is worse for men. ${ }^{3}$ Additionally, CVT cases related to pregnancy/puerperium or hormonal changes have a much better prognosis than those associated with thrombophilia or internal malignancy. ${ }^{8,27}$ Furthermore, those who improve after acute CVT episodes often recover with very few neurological deficits in contrast to arterial stroke cases. However, death or a state of dependency occurs in about $15 \%$ of CVT cases. ${ }^{21}$ Of all CVT syndromes, DVT has the highest mortality rate..$^{5,6,15}$

\section{Conclusion}

Although an uncommon condition, the prompt diagnosis and treatment of CVT can prevent serious and 
potentially fatal outcomes. This study illustrates the varied manifestations of CVT at a tertiary hospital in Oman and highlights the usefulness of prompt imaging to ensure a timely diagnosis. Effective anticoagulation measures ensured good outcomes among the survivors, despite severe neurological deficits at presentation.

\section{CONFLICT OF INTEREST}

The authors declare no conflicts of interest.

\section{FUNDING}

No funding was received for this study.

\section{ADDENDUM}

For a complete table detailing the age, gender, aetiology, symptom duration, clinical features, imaging findings, treatment and outcome of each patient included in this study, please contact the corresponding author.

\section{References}

1. Bousser MG, Ferro JM. Cerebral venous thrombosis: An update. Lancet Neurol 2007; 6:162-70. doi: 10.1016/S1474-4422(07)7 0029-7.

2. Coutinho JM, Zuurbier SM, Stam J. Declining mortality in cerebral venous thrombosis: A systematic review. Stroke 2014; 45:1338-41. doi: 10.1161/STROKEAHA.113.004666.

3. Zuurbier SM, Middeldorp S, Stam J, Coutinho JM. Sex differences in cerebral venous thrombosis: A systematic analysis of a shift over time. Int J Stroke 2016; 11:164-70. doi: 10.1177/174 7493015620708 .

4. Narayan D, Kaul S, Ravishankar K, Suryaprabha T, Bandaru VC, Mridula KR, et al. Risk factors, clinical profile, and long-term outcome of 428 patients of cerebral sinus venous thrombosis: Insights from Nizam's Institute Venous Stroke Registry, Hyderabad (India). Neurol India 2012; 60:154-9. doi: 10.4103/00283886.96388 .

5. Ferro JM, Canhão P. Cerebral venous sinus thrombosis: Update on diagnosis and management. Curr Cardiol Rep 2014; 16:523. doi: 10.1007/s11886-014-0523-2.

6. Bushnell C, Saposnik G. Evaluation and management of cerebral venous thrombosis. Continuum (Minneap Minn) 2014; 20:335-51. doi: 10.1212/01.CON.0000446105.67173.a8

7. Coutinho JM, Gerritsma JJ, Zuurbier SM, Stam J. Isolated cortical vein thrombosis: Systematic review of case reports and case series. Stroke 2014; 45:1836-8. doi: 10.1161/STROKEAHA. 113.004414.

8. Nagaraja D, Taly AB, Das S. Puerperal cerebral venous thrombosis in India. In: Sinha KK, Chandra P, Eds. Progress in Clinical Neurosciences. Ranchi, India: Catholic Press, 1989. Pp. 165-77.

9. Saposnik G, Barinagarrementeria F, Brown RD Jr, Bushnell CD, Cucchiara B, Cushman M, et al. Diagnosis and management of cerebral venous thrombosis: A statement for healthcare professionals from the American Heart Association/American Stroke Association. Stroke 2011; 42:1158-92. doi: 10.1161/STR. 0b013e31820a8364.

10. Palazzo P, Agius P, Ingrand P, Ciron J, Lamy M, Berthomet A, et al. Venous thrombotic recurrence after cerebral venous thrombosis: A long-term follow-up study. Stroke 2017; 48:321-6. doi: 10.1161/STROKEAHA.116.015294.
11. Einhäupl K, Bousser MG, de Bruijn SF, Ferro JM, Martinelli I, Masuhr F, et al. EFNS guideline on the treatment of cerebral venous and sinus thrombosis. Eur J Neurol 2006; 13:553-9. doi: 10.1111/j.1468-1331.2006.01398.x

12. Leach JL, Fortuna RB, Jones BV, Gaskill-Shipley MF. Imaging of cerebral venous thrombosis: Current techniques, spectrum of findings, and diagnostic pitfalls. Radiographics 2006; 26:S19-41. doi: $10.1148 / \mathrm{rg} .26 \mathrm{si055174}$.

13. Ferro JM, Bousser MG, Canhão P, Coutinho JM, Crassard I, Dentali F, et al. European Stroke Organization guideline for the diagnosis and treatment of cerebral venous thrombosis: Endorsed by the European Academy of Neurology. Eur J Neurol 2017; 24:1203-13. doi: 10.1111/ene.13381.

14. Arunodaya GR, Nagaraja D, Srikanth SG, Yasha TC, Vani S, Jayakumar PN, et al. Deep cerebral venous thrombosis: Clinical, CT and autopsy study of 58 cases. In: American Academy of Neurology. 52nd annual meeting abstracts: San Diego, California, USA - April 29-May 6, 2000. Neurology 2000; 54:A1-557.

15. Crawford SC, Digre KB, Palmer CA, Bell DA, Osborn AG. Thrombosis of the deep venous drainage of the brain in adults: Analysis of seven cases with review of the literature. Arch Neurol 1995; 52:1101-8. doi: 10.1001/archneur.1995.00540350095021.

16. Ferro JM, Canhão P, Stam J, Bousser MG, Barinagarrementeria F. Prognosis of cerebral vein and dural sinus thrombosis: Results of the International Study on Cerebral Vein and Dural Sinus Thrombosis (ISCVT). Stroke 2004; 35:664-70. doi: 10.1161/01. STR.0000117571.76197.26.

17. Pillai LV, Ambike DP, Nirhale S, Husainy SM, Pataskar S. Cerebral venous thrombosis: An experience with anticoagulation with low molecular weight heparin. Indian J Crit Care Med 2005; 9:14-18. doi: 10.4103/0972-5229.16263.

18. Ferro JM, Canhão P. Acute treatment of cerebral venous and dural sinus thrombosis. Curr Treat Options Neurol 2008; 10:126-37. doi: 10.1007/s11940-008-0014-0.

19. Kalita J, Chandra S, Misra UK. Significance of seizure in cerebral venous sinus thrombosis. Seizure 2012; 21:639-42. doi: 10.1016/j. seizure.2012.07.005.

20. Gujjar AR, Srikanth S, Mohanty A, Satish S, Srikanth SG, Nagaraja D. Efficacy of decompressive craniectomy for cerebral venous thrombosis with massive infarction: A case series. In: Abstracts of the 5th World Stroke Conference. Stroke 2018; 35:e225-41.

21. Ferro JM, Crassard I, Coutinho JM, Canhão P, Barinagarrementeria F, Cucchiara B, et al. Decompressive surgery in cerebrovenous thrombosis: A multicenter registry and a systematic review of individual patient data. Stroke 2011; 42:2825-31. doi: 10.1161/STROKEAHA.111.615393.

22. Aaron S, Alexander M, Moorthy RK, Mani S, Mathew V, Patil AK, et al. Decompressive craniectomy in cerebral venous thrombosis: A single centre experience. J Neurol Neurosurg Psychiatry 2013; 84:995-1000. doi: 10.1136/jnnp-2012-303356.

23. Siddiqui FM, Dandapat S, Banerjee C, Zuurbier SM, Johnson M, Stam J, et al. Mechanical thrombectomy in cerebral venous thrombosis: Systematic review of 185 cases. Stroke 2015; 46:1263-8. doi: 10.1161/STROKEAHA.114.007465.

24. Mokin M, Lopes DK, Binning MJ, Veznedaroglu E, Liebman KM, Arthur AS, et al. Endovascular treatment of cerebral venous thrombosis: Contemporary multicenter experience. Interv Neuroradiol 2015; 21:520-6. doi: 10.1177/1591019915583015.

25. Coutinho JM, Ferro JM, Zuurbier SM, Mink MS, Canhão P, Crassard I, et al. Thrombolysis or anticoagulation for cerebral venous thrombosis: Rationale and design of the TO-ACT trial. Int J Stroke 2013; 8:135-40. doi: 10.1111/j.1747-4949.2011. 00753.x 
26. Nyberg EM, Case D, Nagae LM, Honce JM, Reyenga W, Seinfeld J, et al. The addition of endovascular intervention for dural venous sinus thrombosis: Single-center experience and review of literature. J Stroke Cerebrovasc Dis 2017; 26:2240-7. doi: 10.1016/j.jstrokecerebrovasdis.2017.05.006.

27. Aguiar de Sousa D, Canhão P, Crassard I, Coutinho J, Arauz A, Conforto A, et al. Safety of pregnancy after cerebral venous thrombosis: Results of the ISCVT (International Study on Cerebral Vein and Dural Sinus Thrombosis)-2 pregnancy study. Stroke 2017; 48:3130-3. doi: 10.1161/STROKEAHA.117.018829.
28. Mendonça MD, Barbosa R, Cruz-e-Silva V, Calado S, VianaBaptista M. Oral direct thrombin inhibitor as an alternative in the management of cerebral venous thrombosis: A series of 15 patients. Int J Stroke 2015; 10:1115-18. doi: 10.1111/ijs.12462.

29. Hiltunen S, Putaala J, Haapaniemi E, Tatlisumak T. Long-term outcome after cerebral venous thrombosis: Analysis of functional and vocational outcome, residual symptoms, and adverse events in 161 patients. J Neurol 2016; 263:477-84. doi: 10.1007/ s00415-015-7996-9. 